Federal Reserve Bank of Minneapolis

Research Department Staff Report 276

August 2000

\title{
Endogenous Policy Choice: The Case of Pollution and Growth
}

\author{
Larry E. Jones \\ Federal Reserve Bank of Minneapolis \\ and University of Minnesota
}

Rodolfo E. Manuelli

University of Wisconsin

\begin{abstract}
What determines the relationship between pollution and growth? Are the forces that explain the behavior over time of these quantities potentially useful to understand more generally the relationship between policies and growth? In this paper, we make a first attempt to analyze the equilibrium behavior of two quantities - the level of pollution and the level of income-in a setting in which societies choose, via voting, how much to regulate pollution. Our major finding is that, consistent with the evidence, the relationship between pollution and growth need not be monotone and that the precise equilibrium nature of the relationship between the two variables depends on whether individuals vote over effluent charges or directly restrict the choice of technology. Moreover, our analysis of the pollution problem suggests that, more generally, endogenous policy choices should be taken seriously as potential sources of heterogeneity when studying cross country differences in economic performance.

*We thank Graziella Bertocchi, V. V. Chari, Hal Cole, Mike Dotsey, Jeremy Greenwood, Arik Levinson, Sergio Rebelo, and Karl Shell; seminar participants at the University of Chicago, Cornell University, Rochester University, University of Minnesota, University of Michigan, University of Wisconsin and the Federal Reserve Bank of Richmond; the editors and referees for their comments; and the National Science Foundation for financial support. The views expressed herein are those of the authors and not necessarily those of the Federal Reserve Bank of Minneapolis or the Federal Reserve System.
\end{abstract}




\section{Introduction}

Recent empirical work suggests that the output of many pollutants is controlled as income grows (for a discussion of the direct evidence on pollution controls and the level of pollution and international movements of pollution in response to these controls, see Low and Yeats (1992); Lucas, Wheeler, and Hettige (1992); Grossman and Krueger (1995); and Levinson (1996)). and. Although the evidence is sketchy at this time, it supports the view that, after passing through a period of high and increasing pollution, eventually, society takes actions to control these external effects. Several patterns emerge from the data. For some pollutants, the relationship between income and pollution follows an inverted U, first increasing and then decreasing, while for others this inverted $U$ is followed by a subsequent sustained increase (see World Bank (1992) and Grossman and Krueger (1995)).

While detailed analyses of the history of pollution controls are scarce, anecdotal evidence abounds. An interesting case study is the experience of the Netherlands' use of effluent charges for the control of water pollution. (These are per unit of pollution costs and are quite common in many European countries. See Wheeler (1992).) Before 1970 no effluent charge was administered whatsoever, while over the next decade this fee rose by 83 percent of its introductory level. The response to this was rapid and stunning: the level of pollutants dropped by 75 percent over that period. This pattern of a dramatic, sudden reduction is repeated in other examples. Another case in point is the history of regulation of DDT in the United States (see U.S. Environmental Protection Agency (1995)). Although the first regulation aimed at controlling DDT usage occurred in 1957, this restriction was limited to use on lands adjacent to those administered by the U.S. Forest Service and had only a minor impact on DDT usage in the country as a whole. By this point, it was already known that DDT was a carcinogen. Until 1970, only minor legislation 
controlling DDT use was enacted. Between 1970 and 1975, however, its use was virtually completely banned.

When confronted with these facts, economists often have the reaction that this follows immediately from standard arguments if a clean environment is a luxury good. The argument is that as income grows, an increasing fraction of scarce resources would be directed at pollution control. Unfortunately, while true (and an important feature of our model), this does not imply that the measured level of pollution should be nonmonotone. Indeed, virtually any time path of pollution is consistent with this observation. As an example of this, it is sufficient to consider a technology in which smoke is proportional to pollution. In this case, it is not possible to simultaneously observe ever increasing consumption and bounded (or nonmonotone) paths for pollutants no matter what the form of preferences over the environment. This highlights the role of an important missing ingredient from the simple story outlined above- the technological link between output and pollution. This link, through the use of cleaner production processes, plays an important role in the model we outline below.

Is it possible that the nature of the political institutions that are used to affect pollution determine whether one or the other path is observed? At least some authors believe that the answer to this question is yes (see Wheeler (1992)). As evidence of this, they point to the fact that pollutant levels are considerably higher in Eastern bloc countries than in countries where democratic processes play a key role.

In this paper, we analyze two distinct models of the extent of pollution regulation through collective decision making. The models have a common approach to the technological side of pollution (different technologies are associated with different amounts of pollution per unit of output), but differ in the details of the political institutions used to bring about pollution control. 
We describe the time paths of income and pollution implied by majority voting in two settings: voting over (proportional) effluent charges and voting over direct regulation of technology, or choice of minimum standards. We show that when voting is over effluent charges, the time path of pollution will follow an inverted $\mathrm{U}$, followed by a sustained increase similar to that described in the empirical literature. An interesting property of this model is that the equilibrium policy chosen has a jump as a function of income. If, instead, individuals vote directly over the "dirtiest" allowable technology, the level of pollution monotonically increases to a bounded level as consumption grows. (There is no discontinuity in the equilibrium policy under this scheme.) Both of these patterns fit well with the empirical evidence in Grossman and Krueger (1995). ${ }^{1}$ Both of these models have the interesting implication that countries at the upper end of the income distribution should converge - at high levels of income, the growth rate of output is a decreasing function of the level of income. This prediction of the model is reminiscent of the finding of convergence clubs discussed in the empirical growth literature (see Durlauf and Johnson (1995) and Quah (1996)).

There are several interesting conclusions to be drawn from this analysis. First, the details of political institutions used to control pollution matter, even for the qualitative properties of the time paths of pollutants. In one, the time path is $\mathrm{S}$ shaped, while in the other it is monotone. Second, although the time paths differ, there are two important common elements. These are that the level of overall pollution is bounded along the equilibrium path and that the limiting value for pollution is the same for both schemes. Finally, the discontinuity in the time path of the effluent

\footnotetext{
${ }^{1}$ In each of these cases, that the environment is a luxury good is an important element-if preferences are homothetic, pollution grows without bound.
} 
charge in the first model is reminiscent of the abrupt changes in regulation that seem to occur in practice.

For comparative purposes, we also study a class of optimal allocations. In this case, we show that the relationship between pollution and income follows an inverted U. Again, the path of pollution is bounded, but is qualitatively different from those in the two voting equilibria. It is not possible to generate an $\mathrm{S}$ shaped time path with this control mechanism in our model, and there is no discontinuity in either the optimal regulation or the level of pollution. To the extent that the paths observed in the data have the S shaped pattern, they suggest that the voting model is a better positive theory. This conclusion is reinforced by the sudden changes in regulation described above. The analysis of the planning outcome also allows us to compare the common limiting value of pollution in the voting models with that from optimal allocations. Whether the equilibrium level is above or below the planner's level depends on how the young (that is, the nonvoters) value a clean environment. From this analysis, we can draw two conclusions. First, the fact that both the planner's problem and the effluent charge voting model give rise to nonmonotone paths shows that we cannot infer from the data that the observed path is either optimal or nonoptimal. Second, the fact that pollution is controlled (that is, bounded) in the data is not an indication that it is optimally controlled.

In the model, pollution is internal in the sense that it affects only the individuals who vote. A straightforward extension of the model shows that if the pollution is external to the political jurisdiction being modeled, the level of the pollutant will grow without bound. This suggests that some sort of political mechanism across countries is necessary to control these global pollutants, but that once in place, this control will occur. Here one of the implications of the analysis is that heterogeneity in income levels across countries that are not fully integrated 
(capital is not mobile) will necessarily imply disagreement about the optimal regulation of global pollutants. Further, the analysis shows that low capital countries would prefer less regulation.

Although there is a large literature on the relationship between economic activity and the environment (see Baumol and Oates (1988) for a textbook treatment of the relevant static theory), there are few papers that explicitly model the equilibrium relationship between growth and environmental degradation. In the endogenous growth literature, the recent work by Fisher and van Marrewijk (1994) and Mohtadi (1994) is closest to our own. Both of these papers model the environment as an additional factor of production and concentrate on the impact of different criteria that a planner might choose to allocate this environmental input between households and firms. The key difference is that in our formulation, public policy is endogenously determined. Stokey (1998) studies economies in which a central planner chooses the optimal allocation when individuals are infinitely lived. She shows conditions for balanced growth and discusses the relative merits of tax and voucher schemes over direct regulation. She does not address the issue of implementation; that is, she does not study whether the optimal policies she describes can be supported as the equilibrium policies of some collective decision-making mechanism.

Finally, our analysis of the pollution problem suggests that, more generally, endogenous policy choices should be taken seriously as potential sources of heterogeneity when studying cross-country differences in economic performance. Our key source of cross-country heterogeneity is policy endogeneity (see also Glomm and Ravikumar (1992 and 1995), Alesina and Rodrik (1994), Persson and Tabellini (1994), and Krusell, Quadrini, and Rios-Rull (1997)). We show that the equilibrium relationship between growth rates of capital and income levels displays an inverted U shape when individuals vote over effluent charges. This theoretical implication, which is consistent with the findings of Easterly (1994) and Cho (1996), provides an alter- 
native interpretation to the standard view that such a relationship must be generated by models of nonconvexities and/or multiple equilibria. The overall message from this research is clear: on the one hand, our positive results make us optimistic about the ability of the model to explain stylized facts about pollution and growth. On the other hand, the sensitivity of the outcome to the details of institutions suggests that the effects of introducing endogenous policy choice are hard to predict in environments, like the one in this paper, in which income matters.

The paper is organized as follows. Section 2 lays out the basic model and studies the equilibrium in which individuals vote over effluent charges. Section 3 describes the dynamic behavior of such an equilibrium. Section 4 studies the case in which individuals vote over minimum quality or environmental standards. Section 5 presents a class of optimal allocations. Finally, Section 6 suggests some possible extensions and offers some concluding comments.

\section{The Basic Model With Effluent Charges}

We consider an economy that has available a wide range of productive techniques that differ according to both their costs of production and their environmental effects. The choice, by firms, among techniques is influenced not only by price but also by restrictions on use imposed by the government. To model this aspect of firm decision making, we adopt the assumption that the government sets technique-specific taxes with the aim of controlling pollution (in Section 4, we consider the case in which the government institutes minimum quality standards). From a formal point of view, these are equivalent to the effluent charge systems used in many countries. Interpreted broadly, however, these environmental taxes should be viewed as incorporating a wide array of regulations and other forms of control that result in an increase in the effective price of environmentally pernicious techniques. 
We will use a growth model with two-period lived overlapping generations. An implication of this is that voting decisions are made by individuals with short horizons; thus, the generational structure and the natural voting scheme that we study (more on this later) allow us to capture a realistic feature of actual economies. To guarantee that, in the absence of pollution, the equilibrium displays growth and is optimal, we study a two-sector model with (potentially infinitely many) differentiated capital stocks. We assume that all forms or vintages of capital are perfect substitutes in production, while they differ both in terms of cost of production and in how much pollution their use generates. In order to make the problem interesting, we consider the case in which environmentally cleaner capital goods are more costly to produce.

The nature of pollution that we model is local in both the physical and temporal dimensions. Since we analyze a model in which voters have full control over all polluting activities, it is probably best to interpret our results as applying to pollution that is local in nature (that is, restricted to the voting region). In the temporal sense, we first consider the case in which the level of pollution produced at time $t$ affects only the members of generation $t-1$ without any direct generational spillovers. Although there are no direct effects, policy decisions on the part of one generation affect the well-being of future generations through their impact on capital accumulation decisions. This second assumption is not critical and can be relaxed.

We assume that successive generations play a voting game in taxes on polluting activities. Individuals born at time $t$ vote on pollution taxes that will be in effect at time $t+1$. Their realized utility, $V_{t}\left(\tau_{1}, \tau_{2}, \ldots\right)$, is the voter's utility function over consumption and pollution paths evaluated at a competitive equilibrium given the sequence of taxes. The function $V_{t}$ could (potentially) depend on the entire sequence of taxes chosen. We will examine subgame perfect equilibria of this voting game. As is well known, there are typically many equilibria in multi- 
agent voting games. We consider a representative agent model and simply select the equilibrium that corresponds to the best policy from the perspective of the representative agent. Even with this restriction, in general, very little can be said about the equilibrium outcomes of voting games of this type. Because of this, we will simplify the problem by going to a special overlapping generations formulation. In essence, we will put enough restrictions on preferences and labor endowments so that $V_{t}$ depends only on current and past tax rates. Moreover, for our specification, it will be true that the only way that previously chosen taxes matter for an individual of generation $t$ is through their impact on the capital stock at the beginning of time $t$. In Section 6, we discuss extensions to settings with heterogeneous agents.

To begin, we will describe the economic environment and the competitive equilibrium that results from an arbitrary sequence of taxes. This determines the form of $V_{t}$. We will then analyze the voting game given this indirect utility function over tax sequences.

\section{Preferences}

Consumer preferences are given by

$$
\log c_{t}^{t}+\beta \log c_{t+1}^{t}-u\left(s_{t+1}\right)
$$

where $c_{j}^{i}$ is consumption in period $j$ of the individual born at time $i$ and $s_{i}$ is pollution at time $i$. We assume that individuals are endowed with one unit of labor in their first period of life and none in the second. Their endowments of all other goods are zero. Thus, they face the budget constraint $c_{t}^{t}+b_{t} \leq w_{t}$ in their first period of life and $c_{t+1}^{t} \leq\left(1+i_{t+1}\right) b_{t}$ in their second period of life, where $\left(1+i_{t+1}\right)$ is the interest rate between time $t$ and time $t+1$. Given these preferences, individuals derive disutility from the level of pollution in their second period of life. Given the assumptions about voting, it is possible without changing the basic results to make preferences de- 
pend on the level of pollution when young if the separability assumption is maintained. We chose this simpler framework to simplify the presentation. We assume that $u$ is increasing, convex, and $C^{2}$. These preferences imply that saving is not responsive to interest rates and hence greatly simplify the analysis of the voting game. In particular, these preferences imply that, as noted above, only current and past taxes will enter the voter's indirect utility function.

Consumers maximize utility by choosing consumption in each period of their lives, taking after-tax prices as given and beyond their control. It is standard to show that optimal decisions are completely summarized by a saving function, which in this case is given by

$$
b_{t}=(\beta /(1+\beta)) w_{t} \text {, }
$$

where $w_{t}$ is the wage rate at time $t$ and $b_{t}$ is the level of savings. First period consumption at time $t, \quad c_{t}^{t}$, is $(1 /(1+\beta)) w_{t}$. Second period consumption of an individual born at time $t$ is $c_{t+1}^{t}=$ $\left(1+i_{t+1}\right)(\beta /(1+\beta)) w_{t}$. It follows that the indirect utility function is

$U^{t}=\mathrm{constant}+(1+\beta) \log w_{t}+\beta \log \left(1+i_{t+1}\right)-u\left(s_{t+1}\right)$

The equilibrium determination of $w_{t}, i_{t+1}$, and $s_{t+1}$ depends on the details of the technology and is the focus of the remainder of this section.

\section{Technology}

On the production side, we assume that there is one consumption good produced in each period and a (potentially infinite) number of different capital goods indexed by cleanliness, $z$, with higher $z$ indicating a cleaner technology. Let $k_{c t}(z)$ denote the amount of capital of type $z$ that is used in production of the consumption good. We assume that output in this sector depends only

on the total amount of capital used, $k_{c t}=\int_{0}^{\infty} k_{c t}(z) d z$, and labor, $n_{t}$, according to 


$$
c_{t}=B k_{c t}^{\alpha} n_{t}^{1-\alpha}
$$

This formulation implies that the different capital goods are perfect substitutes in production, and hence quality choice will be driven completely by cost considerations. Although we allow firms to choose either finitely or infinitely many qualities of capital, due to the nature of the cost functions that we will use, it will follow that only one quality level will be chosen in any period.

To simplify, we consider a situation in which capital is fully malleable. At the beginning of time $t$, the existing stock of capital, $k_{t}$, can be used to produce either capital goods of type $z$ to be used in the consumption sector or to produce generic capital that will be used in the investment sector. Formally, the investment side of the economy can be summarized by

(2.2a) $k_{t}=\int_{0}^{\infty} m(z) k_{c t}(z) d z+x_{t}$

(2.2b) $k_{t+1}=(1-\delta)\left[k_{c t}+x_{t}\right]+A x_{t}$,

where

$$
k_{c t}=\int_{0}^{\infty} k_{c t}(z) d z
$$

One interpretation of this formulation is that, at the beginning of time $t$, capital is split into (basic) consumption capital and investment capital. We assume that the production of new capital is linear in the capital goods allocated to the investment sector $x$ - output of the investment sector is $A x_{t}$. In this formulation, $m(z)$ is the amount of general capital (that is, $k$ ) necessary to produce one unit of type $z$ capital. We assume that $m(z)$ is increasing and convex in $z$. We also assume that $m(0)=1$, which implies that type $z=0$ consumption capital and investment capital are perfect substitutes and, hence, have the same rental rate. The cost $m(z)$ should be interpreted as a flow; that is, in every period, if the firm wants to operate capital of type $z$, it must spend the extra $m(z)-1$ units of capital necessary to convert general capital into type $z$ capital. This simplifies 
the algebra for the standard reasons: we do not have to keep track of the distribution of old vintages in calculating the equilibrium. Note that if quality choices were restricted to be only $z=0$, we would have a standard two-sector growth model.

At the end of the period, both the stock of capital that was used in the investment sector $x_{t}$ and that used in the consumption sector $k_{c t}$ are depreciated at rate $\delta$. Thus, capital at time $t+1$ is $(1-\delta)\left[k_{c t}+x_{t}\right]+A x_{t}^{2}$

Firms in the investment sector use general capital to produce capital available for use in the following period. These firms can use only the $z=0$ technology. The production function is linear: it uses one unit of capital today to produce $A$ units of new capital tomorrow.

We assume that pollution-or smoke, which we denote by $s$-is associated with the use of capital in the consumption sector. More precisely, the total amount of pollution is given by

$$
s_{t}=\int_{0}^{\infty} \phi(z) k_{c t}(z) d z
$$

where $\phi(z)$ is the amount of (flow) smoke generated by one unit of capital in the consumption sector operated at cleanliness level $z$. We assume that $\phi(z)$ is convex and decreasing so that higher index goods (higher quality) are less polluting, but there is a diminishing marginal reduction in the change of pollution per unit of capital.

There are several features of our technology that are worth emphasizing: First, it assumes that there are no clean and dirty goods, but there are clean and dirty production techniques. This

${ }^{2}$ Since a period in this model corresponds to a generation, $\delta$ is a large number. For $\delta=1$, there is no distinction between the flow interpretation and the case in which all the capital maintains its original vintage. 
goes one step beyond the smoke-in-the-production-technology function. This model does not generate a simple reduced form in which smoke (and no other endogenous variables) enters the production technology. Second, we assume that the capital goods-producing industry does not contribute to pollution. This assumption can be relaxed, but not completely. See the comments in Section 6. Finally, our smoke variable depends only on activities in the consumption sector today; that is, it is a flow variable (past smoke does not matter). We discuss an extension to the case in which pollution has a cumulative, or a capital-like component, in Section 6.

We assume that a firm in the consumption sector that rents capital of type $z$ has to pay both the rental price, $r_{k t}(z)$, and the pollution tax, $\tau_{t}(z)$. We restrict the shape of the function $\tau_{t}(z)$ to be proportional to the amount of pollution produced, $\tau_{t}(z)=\tau_{t} \phi(z)$. This implies that the representative firm producing consumption solves the following problem:

$$
\max _{k_{c t}(z), n_{t}} B\left(\int_{0}^{\infty} k_{c t}(z) d z\right)^{\alpha} n_{t}^{1-\alpha}-w_{t} n_{t}-\int_{0}^{\infty}\left(1+\tau_{t} \phi(z)\right) r_{k t}(z) k_{c t}(z) d z
$$

where $w_{t}$ is the wage rate. The firms producing new investment goods solve

$$
\max _{x_{t}} p_{k t} A x_{t}-r_{k t}(0) x_{t}
$$

where $p_{k t}$ is the price of new capital available for production at time $t+1$. To simplify the notation, we use $r_{k t}(0)=r_{I t^{*}}$. The firms that transform basic capital into its different types solve

$$
\max _{k_{c t}(z), x_{t}, k_{t}} \int_{0}^{\infty} r_{k t}(z) k_{c t}(z) d z+r_{I t} x_{t}-r_{I t} k_{t}
$$

subject to

$$
\int_{0}^{\infty} m(z) k_{c t}(z) d z+x_{t} \leq k_{t}
$$


Finally, to keep the presentation simple, we assume that the tax revenues (from the pollution taxes) are used to provide some good that enters separably in the utility function. We assume that individuals ignore the connection between tax revenues and this good.

\section{Equilibrium}

For a given tax sequence $\left\{\tau_{t}\right\}$, we define an equilibrium as follows.

Definition: An equilibrium is a set of sequences $\left[c_{t}^{t-1}, c_{t}^{t}, k_{t+1}, z_{t}, s_{t}, k_{c t}(z), x_{t}, p_{k t}, r_{k t}(z), r_{I t}, 1+\right.$ $\left.i_{t+1}, \tau_{t}, t \geq 0\right]$, such that

(i) For all $\mathrm{t} \geq 0, c_{t}^{t}, c_{t+1}^{t}$ solve the consumer's maximization problem.

(ii) $c_{0}^{-1}$ is equal to $p_{k 0} k_{0}$.

(iii) Firms maximize profits.

(iv) $b_{t}=p_{k t} k_{t+1}$ (market clearing).

(v) $\left[p_{k t+1}(1-\delta)+r_{I t+1}\right] / p_{k t}=1+i_{t+1}$.

(vi) The tax $\tau_{t}$ is chosen, using a majority voting mechanism, by members of the generation born at $t-1$.

This definition does not require further elaboration, except to point out that when making consumption-saving decisions, individuals take as given all taxes, as well as the equilibrium level of pollution. However, separability of the utility derived from consumption and the disutility associated with pollution imply that consumption-saving decisions are made independently of the level of pollution.

Since the equilibrium outcome for a given tax sequence $\left\{\tau_{t}\right\}$ is rather standard, we relegate (most of ) its analysis to Appendix A. However, there is one aspect-the optimal choice of 
cleanliness level, $z$, as a function of the tax rate - that is both nonstandard and important for our results. Even though it is possible to conduct the analysis at a fairly general level, the basic intuition can be fully captured in a simple setting in which we specialize the functions describing the flow cost of producing high quality goods, $m(z)$, as well as the pollution per unit of capital $z$, $\phi(z)$. Specifically, we assume

(2.4a) $m(z)=(1+z)^{\theta}, \theta>0$

and

(2.4b) $\phi(z)=D(1+\mathrm{z})^{-v}, v>0, v>\theta \geq 1$.

Since all types of capital goods are perfect substitutes in the consumption sector and there are linear transformation curves between any two types (with slope $m(z) / m\left(z^{\prime}\right)$ ), it follows that $r_{k t}(z)=m(z) r_{k t}(0)=m(z) r_{I t}$. It follows that cost minimization on the part of the firms in the consumption sector implies a choice of $z$ that solves

(P.1) $\min _{z}\left(1+\tau_{t} \phi(z)\right) r_{k t}(z)=\left(1+\tau_{t} \phi(z)\right) m(z) r_{I t}$

The properties of this maximization problem are summarized in Proposition 1:

Proposition 1. The solution to problem (P.1) is given by $z(\tau)=0$ for $\tau \leq \tau_{L}$, and

$$
z(\tau)=\left(\frac{(\nu-\theta) \tau D}{\theta}\right)^{1 / v}-1, \text { for } \tau \geq \tau_{L} \text {, where } \tau_{L} \text { is given by } \tau_{L}=\theta /[(\nu-\theta) D]
$$

Proof: See Appendix B.

Proposition 1 shows that for tax levels that fall short of $\tau_{L}$, there will be no impact on the equilibrium level of the quality of capital good chosen. Hence, there is a kink in the optimal 
choice of quality: for relatively low tax rates, there is no quality upgrade; however, as taxes increase, firms upgrade their capital goods to cleaner ones.

The voters born at time $t$ are affected by their choice of $\tau_{t+1}$ in two ways. First, higher taxes at time $t+1$ hurt generation $t$ because they lower the rate of return between time $t$ and time $t+1$. Second, higher taxes will both increase the quality of capital goods used in the consumption sector at time $t+1$ and reduce the quantity of capital allocated to the consumption sector, thereby reducing the amount of pollution at time $t+1 .^{3}$

Optimal behavior on the part of capital goods producers implies that $r_{I t+1}=A p_{k t+1}$. Using this and the definition of equilibrium, we have that

$$
1+i_{t+1}=\frac{p_{k t+1}(1-\delta)+r_{I t+1}}{p_{k t}}=\frac{p_{k t+1}(1-\delta+A)}{p_{k t}} \text {. }
$$

Now, at the time of voting, $p_{k t}$ is fixed, independent of $\tau_{t+1}$ (see Appendix A), and hence, the only element that depends on $\tau_{t+1}$ is $p_{k t+1}$. Thus, the key channel through which taxes affect consumption of voters is through their impact on the unit price of capital.

It is shown in Appendix A that the equilibrium choice of $z$ at time $t+1$ depends just on $\tau_{t+1}$. Hence, it follows that total pollution (see (2.3)), is

$$
s_{t+1}\left(\tau_{t+1}\right)=\phi\left(z_{t+1}\left(\tau_{t+1}\right)\right)\left[k_{c t+1}\left(z_{t+1}\left(\tau_{t+1}\right)\right) / k_{t+1}\right] k_{t+1}=\mu\left(\tau_{t+1}\right) k_{t+1},
$$

\footnotetext{
${ }^{3}$ There are several potential additional avenues for the effects of taxes that are not important because of the special assumptions we have made. First, consumption in a voter's first period of life is a constant fraction of wages. In Appendix A, it is shown that wages at $t$ are independent of $\tau_{t+1}$. Thus, first period consumption does not depend on voters' tax rate. Second, consumption in voters' second period of life is equal to the rate of return times saving. But savings — which are just wages minus consumption-do not depend on the taxes voters will choose. (It is at this point that our assumption that saving is inelastic with respect to the interest rate becomes quite convenient.) Thus, it is only the rate of return that affects second period consumption.
} 
where we are using the result (see Appendix A for a derivation) that both $z_{t+1}$ and the ratio $k_{c t+1}\left(z_{t+1}\right) / k_{t+1}$ depend on just the tax rate that will be chosen at $t+1, \tau_{t+1}$.

To summarize this discussion, it follows that voters' utility function over taxes is given by

$$
V_{t}\left(\tau_{1}, \ldots\right)=\log c_{t}^{t}\left(\tau_{1}, \ldots\right)+\beta \log c_{t+1}^{t}\left(\tau_{1}, \ldots\right)-u\left(s_{t+1}\left(\tau_{1}, \ldots\right)\right)
$$

First, note that the effects of $\tau_{1}$ through $\tau_{t-1}$ on the voter's utility is completely summarized through their effect on $k_{t}$. Moreover, since all of these variables are predetermined and utility is separable, the term $\log c_{t}^{t}\left(\tau_{1}, \ldots\right)$ is independent of the voter's choice. For similar reasons, both $c_{t+1}^{t}\left(\tau_{1}, \ldots\right)$ and $s_{t+1}\left(\tau_{1}, \ldots\right)$ can be written as functions of $k_{t+1}$ and $\tau_{t+1}$ only. Finally, because of the independence of savings from the interest rate, it follows that $k_{t+1}$ does not depend on $\tau_{t+1}$. These considerations imply that the voter's problem is equivalent to maximizing

$$
\beta \log c_{t+1}^{t}\left(\tau_{t+1} ; k_{t+1}\right)-u\left(s_{t+1}\left(\tau_{t+1} ; k_{t+1}\right)\right)
$$

where $k_{t+1}$ is taken as given. Note that $c_{t+1}^{t}\left(\tau_{t+1} ; k_{t+1}\right)=p_{k t+1} k_{t+1}$. The arguments in Appendix A show that $p_{k t+1} k_{t+1}$ is of the form $p_{k \tau}\left(\tau_{t+1}\right) k_{t+1}^{\alpha}$, where the subscript $\tau$ is to remind the reader that these are the equilibrium values when individuals vote over tax rates. Because of our choice of $\log$ utility and the independence of $k_{t+1}$ from $\tau_{t+1}$, it follows that the voter's objective function is

$$
V(\tau, k)=\beta \log \left[p_{k \tau}(\tau)\right]-u\left[\mu_{\tau}(\tau) k\right]
$$

To describe the equilibrium of the voting game, it is necessary to determine the properties of $p_{k \tau}(\tau)$ and $\mu_{\tau}(\tau)$. These are summarized in Appendix A. The key properties that affect the qualitative nature of the equilibrium are that, although these functions are continuous, first, they 
are not differentiable at $\tau=\tau_{L}$, and, second, the price of basic capital, $p_{k \tau}(\tau)$, is not necessarily decreasing in $\tau$.

Given our choice of functional forms for $m$ and $\phi$, it is useful to introduce the variable $y=$ $\left(\tau / \tau_{L}\right)^{\theta / v}$ to simplify notation. Individuals can be seen as voting over $y$ directly. Note that under this notation, $y \leq 1$ if and only if $\tau \leq \tau_{L}$. Thus, $y \leq 1$ corresponds to no effective pollution control, $z=0$, while $\mathrm{y}>1$ corresponds to $z>0$.

Let $k_{A}$ be defined by

$$
\beta \alpha+\beta[\alpha(1+\beta) /(1-\alpha) \beta][1+\theta /(v-\theta)]^{-1}=u^{\prime}\left(\mu_{1}(1) k_{A}\right) \mu_{1}(1) k_{A} .
$$

Given our assumptions about $u$, it is clear that $k_{A}$ both exists and is unique.

Assumption A: There exists a $(k, y)$ pair with $k<k_{A}$ and $0 \leq y<1$, such that

$$
\beta \alpha+\beta[\alpha(1+\beta) /(1-\alpha) \beta]\left[1+\theta /(v-\theta) y^{v / \theta}\right]^{-1}<u^{\prime}\left(\mu_{1}(y) k\right) \mu_{1}(y) k
$$

Proposition 2. Under Assumption A, the maximum of $V(y, k)$ is well defined for all $k \geq 0$, and $y(k)$ has the following properties:

(i) For low $k, y(k)=0$; that is, $\exists k_{B}>0$, such that $\forall k \leq k_{B}, y(k)=0$.

(ii) For large $k, y(k)$ is continuous and increases without bound; that is, $\exists k_{C}$, such that for all $k \geq k_{C}, y(k)$ is continuous, is increasing, and $\lim _{k \rightarrow \infty} y(k)=\infty$.

(iii) There is at least one upward jump discontinuity in $y(k)$.

(iv) For moderate $k$, changes in $k$ do not induce any change in quality, although there may be changes in taxes; that is, $\exists k_{D}$ and $k_{E}$, such that for all $k \in\left(k_{D}, k_{E}\right), z(y(k))=z\left(y\left(k_{D}\right)\right)$. 
(v) If $y(k)$ is differentiable in the region in which $y \leq 1$, then there is a $k_{F}$, such that for all $k \leq k_{F}, y(k) \leq 1$; for $k \geq k_{F}, y(k) \geq 1$; and $y$ is continuous in these two regions. Thus, $y(k)$ jumps upward at $k_{F}$ and is continuous otherwise.

Proof: See Appendix B.

In words, what Proposition 2 says is that for small values of $k$ (that is, in low income per capita countries), pollution taxes are chosen to be zero. As $k$ increases, $y$ increases but stays in the region $y \leq 1$. In this region, nonzero taxes are chosen by voters not to control pollution (since $z=0$ when $y \leq 1$ ), but rather to manipulate the rate of return on capital to voters' benefit. This is a common property of voting equilibria in economic models-voters strategically manipulate prices (here, interest rates) for their own benefit in the equilibrium outcomes of the economic system. Finally, for sufficiently high levels of $\mathrm{k}$, the equilibrium tax is greater than $\tau_{L}$ (that is, $y>$ $1)$, and it grows without bound as a function of $k$. The transition from the low tax region $(y \leq 1)$ to the high tax region $(y \geq 1)$ is not smooth. Specifically, we show that there exists a level of $k$, denoted by $k_{F}$, such that $y(k)$ is discontinuous at $k_{F}$. The discontinuity is of a very simple form: $y$ jumps upward at $k_{F}$.

It is easy to check that even though we assume that $u$ is convex, most of the analysis goes through as long as $u$ is not too concave. In particular, if $u=\log$, the equilibrium tax rate is independent of $k$, and pollution increases monotonically with income, and the model converges in one period to a balanced growth path.

Even though Proposition 2 contains the basic result, it is useful to more carefully analyze what kind of time path for taxes and pollution are implied by it. We now turn to that task. 


\section{The Dynamics on the Equilibrium Path}

It is of interest to analyze what kind of time paths for income and pollution-the variables selected by Grossman and Krueger (1995)—are implied by this model. The previous section showed the nature of the equilibrium as a function of the aggregate capital stock. In Appendix A, we detail the implications of the model for the growth rate of capital. Here, it suffices to say that under standard assumptions (that is, the productivity in the production of investment goods is sufficiently high), the model displays positive growth for all possible values of the tax variable $y$. Given this, the time path of capital is simple: it increases without bound. Thus, it is simple to describe the time path of the relevant endogenous variables using Proposition 2. Let $\gamma(y)$ be the growth rate of the capital stock when the tax rate is equal to $y$. We collect the main results in the following proposition.

Proposition 3. Assume that Assumption A holds, that $\gamma(y)>\gamma(\infty)>1$ for all $y$, and that the initial capital stock, $k_{0}$, is small.

(i) There is some $t_{0}^{*}$, such that for $0 \leq t \leq t_{0}^{*}$

(a) the equilibrium tax rate $y_{t}$ is zero,

(b) the growth rate of capital is constant and equal to $\gamma(0)$,

(c) pollution is increasing.

(ii) There is a $t_{1}^{*}>t_{0}^{*}$, such that for all $t$ between $t_{0}^{*}$ and $t_{1}^{*}$

(a) the equilibrium tax rate is increasing, but $y_{t} \leq 1$,

(b) the growth rate of capital is increasing over time,

(c) the level of pollution is decreasing. 
(iii) At $t=t_{1}^{*}$

(a) the equilibrium tax rate jumps up to a value of $y>1$,

(b) the level of pollution jumps down.

(iv) For $t>t_{1}^{*}$

(a) the level of pollution increases over time and converges to $s_{\tau}^{*}$, where $s_{\tau}^{*}$ satisfies

$$
u^{\prime}\left(s_{\tau}^{*}\right) s_{\tau}^{*}=\beta \alpha /(1+v / \theta)
$$

(b) the tax rate is increasing over time and converges to $\infty$,

(c) the growth rate of capital is decreasing over time and converges to $\gamma(\infty)>1$.

(v) The asymptotic growth rate of consumption, $\gamma_{c}(\infty)$, is strictly greater than one.

Proof: This follows directly from an application of Proposition 2, since $\gamma(y)>1$ for all $y$.

An interesting implication of Proposition 3 is that the time path of pollution is not monotone. An example is shown in Figure 1. After an initial period in which pollution increases and taxes are zero, there is a period of relatively low taxes, no quality upgrades, and decreases in the level of pollution. This is induced by a change in the composition of capital: more capital is allocated to producing investment goods and less capital to producing capital goods used in the production of consumption goods. Since the latter are the pollution-causing factors, total pollution decreases.

As income grows, voters choose to induce - through higher taxes-a quality upgrade. In the model, this takes the form of a discrete increase, a jump, in the tax rate. In the period in which the jump occurs-recall that a period is roughly half a generation in this model—output 
drops. In this period, higher taxes induce a quality upgrade and pollution drops, because cleaner capital goods are used in the consumption sector.

After the transition period, the economy is in a new regime in which tax rates, as measured by $y_{t}$, increase over time and pollution per unit of capital decreases, because cleaner capital goods are used in equilibrium. What happens to measured pollution taxes? Recall that the actual tax rate per unit of capital is $\tau \phi(z)$. As $y$ increases without bound, $\tau$ increases as well, but $z(y)$ increases, and hence, $\phi(z)$ decreases. Thus, the endogenous response works in the direction of reducing the measured tax rate. For the example that we have analyzed, measured taxes, defined as $\tau \phi(z)$, equal $\theta /(v-\theta)$ (see Appendix A). Thus, observations on measured taxes and pollution levels (or quality of the capital stock) could lead an observer to incorrectly infer that the price mechanism is not important to induce environmental protection when, in fact, exactly the opposite is true. In this region, both income and pollution grow, although pollution grows at a slower rate. In the long run, pollution is bounded and income is growing; hence, pollution, as a fraction of income, disappears. Note that this does not imply that people do not care about pollution. Actually, the opposite is true: at high income levels, voters choose taxes to induce very high quality choices; hence, they choose to pay a large penalty, in terms of resources used to operate cleaner technologies, relative to output.

\section{Regulating Quality Choice}

An alternative institution that can be used to enforce environmental standards is direct quantitative restrictions. For example, in the United States there is a quantitative restriction on the number of leaded-gasoline-burning car engines that can be sold: it is zero. This type of quantitative restriction is common in many environmental regulations. One way of modeling quantitative restrictions is to allow the voters at time $t$ to collectively choose a minimum level of quality $z$. In 
other words, at time $t$ the old vote on a level of quality $z_{t}$ and firms cannot use any variety $z$, with $z<z_{t}$. (Alternatively, one can interpret this scheme as a different simplification of the tax rules where $\tau=\infty$ for all $z<z_{\tau}$, for some $z_{\tau}$, and $\tau=0$ for $z \geq z_{\tau}$.) It turns out that the equations describing the equilibrium for a given value of the tax rates hold with $\tau_{t}$ equal to zero. The reason for this is simple: if the policy specifies that the lowest available quality is $z_{t}$, then firms will choose capital of quality exactly equal to $z_{t}$ since all forms of capital are perfect substitutes. The market price of capital will be $m\left(z_{t}\right) r_{I t}$, and firms optimize taking this as given.

It is useful to describe how the key variables vary with $z$. First, consider the price of capital. Simple calculations detailed in Appendix A show that $p_{k q}(z)$ (here the subindex $q$ indicates that the collective decision is over qualities), the price of capital, is given by

$$
p_{k q}(z)=M k^{\alpha-1}\left[a_{0} m(z)-a_{1}\right]^{1-\alpha} / m(z)
$$

where $a_{0}=1+[\alpha(1+\beta)(1-\delta+A)] /[(1-\alpha) \beta A], a_{1}=\alpha(1+\beta)(1-\delta) /[(1-\alpha) \beta A]$, and $M=\left(a_{0}-1\right) \alpha B / A$. If $a_{1} / \alpha a_{0}>1$, denote by $z_{M}$ the value of $z$ satisfying $m\left(z_{M}\right)=a_{1} / \alpha a_{0}$. If $a_{1} / \alpha a_{0} \leq 1$, set $z_{M}=0$. As in the case in which the collective decision making is over taxes, there is a value of the policy variable - which we denote by $z_{M}$ - that maximizes the value of capital and, hence, the value of consumption of the voters - the old. Note that, in equilibrium, the minimum allowable quality level will be always at least equal to $z_{M}$. Voters will always extract the monopoly surplus. It can be easily verified that the function $p_{k q}(z)$ is decreasing for $z \geq z_{M}$. In order to avoid unnecessary notation, we will concentrate on the case in which $z_{M}=0$.

The amount of pollution per unit of total capital is given by

$$
\mu_{q}(z)=D\left(a_{0}-1\right)\left[(1+z)^{v}\left(a_{0} m(z)-a_{1}\right)\right]^{-1} \text {. }
$$


This function is strictly decreasing for all values of $z$. Thus, the higher the minimum quality level, the lower the amount of pollution per unit of output.

In this case, the rate of growth in total capital is,

$$
\gamma_{k q}(z)=(1-\delta+A)\left[1+\left(a_{0} m(z)-a_{1}\right) / m(z)\right]^{-1}
$$

which is decreasing for all values of $z$.

Finally, the relevant voting function for this case is just

$$
V_{q}(z, k)=\beta \ln \left(p_{k q}(z)\right)-u\left(\mu_{q}(z) k\right)
$$

The next proposition summarizes the behavior of the relevant variables under this equilibrium.

Proposition 4. Assume that the initial capital stock $k_{0}$ is sufficiently small. Then the following are true.

(i) There is some $t_{0}^{*}$, such that for $0 \leq t \leq t_{0}^{*}$,

(a) the equilibrium minimum quality $z_{t}$ is zero,

(b) the growth rate is constant and equal to $\gamma_{q}(0)$,

(c) pollution is increasing.

(ii) For $t>t_{0}^{*}$,

(a) the equilibrium minimum quality is increasing, and it grows without bound,

(b) the growth rate of total capital is decreasing over time,

(c) the level of pollution is increasing, and it converges to $s_{q}^{*}$, where $s_{q}^{*}$ satisfies

$$
u^{\prime}\left(s_{q}^{*}\right) s_{q}^{*}=\beta \alpha /(1+v / \theta)
$$


Remark: If $z_{M}>0$, then the chosen quality is strictly increasing for all values of $k$ and converges to $z_{M}$ as $k$ converges to zero. Thus, in terms of time paths, it is increasing and bounded below by $z_{M}$

Proof: See Appendix B.

The behavior of pollution over time (as well as the minimum quality $z_{t}$ ) is shown in Figure 2. When individuals regulate technologies, the economy displays an ever increasing level of pollution. This level grows faster during the initial period in which the minimum quality is given by $z_{M}$. After $t_{0}^{*}$, the increase in environmental standards decreases pollution per unit of output. However, the growth effect of output dominates, resulting in an increasing level of pollution. Finally, this scheme succeeds in controlling pollution even in a growth environment: the asymptotic level of pollution is finite; moreover, it coincides with $s_{\tau}^{*}$-the limiting level of pollution under the scheme in which taxes are used to regulate pollution. Thus, although the time paths of the two regimes are quite different, their asymptotic or long-run behavior is the same. From a practical point of view, this example points out the limitations of using long-run or balanced growth arguments to interpret data. In this case, if one were interested in using the evidence to distinguish between the two possible regimes, ignoring the transition phase would be equivalent to giving up the possibility of identifying the correct regime.

\section{A Class of Optimal Allocations}

So far, we have characterized the time path and the asymptotic behavior of pollution and income in two equilibrium regimes. In both cases, the old at time $t$ vote on either effluent charges or minimum quality standards to be implemented at $t$, and the collective decision is made using 
majority voting. There are several concerns that arise: Do the qualitative properties of the time path of pollution from the planner's problem agree with either the tax equilibrium or the regulation equilibrium? How does the limiting level of pollution in the voting systems compare with the optimal levels of pollution?

It is well known that in overlapping generations models it is difficult to fully characterize the class of optimal allocations. However, in order to get an idea of the nature of optimal pollution paths, we consider a simple utilitarian social preference function. Let $U_{t}$ be the utility of generation $t$, and assume that the planner maximizes

$$
\text { (5.1) } W=\sum_{t=0}^{\infty} \beta_{P}^{t} U_{t}
$$

subject to the feasibility constraints. The discount factor $\beta_{P}$ is assumed to be between zero and one. The time path of the optimal solution is summarized in the next proposition.

Proposition 5. Assume that $\beta_{P}(1-\delta+A)>1$ (to guarantee that the planner would be willing to grow) and that the initial capital stock $k_{0}$ is sufficiently small. Then the solution to the planner's problem is such that

(i) There is some $t_{0}^{*}$, such that for $0 \leq t \leq t_{0}^{*}$,

(a) the optimal level of quality $z_{t}$ is 0 ,

(b) the growth rate is constant and equal to $\gamma_{p}(0)$,

(c) the level of pollution is increasing.

(ii) For $t>t_{0}^{*}$,

(a) the optimal quality level is increasing and converges to $\infty$ as $t$ goes to $\infty$,

(b) the growth rate of total capital is decreasing over time, 
(c) the level of pollution is decreasing, and it converges to $s_{p}^{*}$, where $s_{p}^{*}$ satisfies

$$
u^{\prime}\left(s_{p}^{*}\right) s_{p}^{*}=\left(\beta+\beta_{P}\right) \alpha /(1+v / \theta)
$$

Proof: See Appendix B.

There are some interesting differences between the planner's allocation and the allocations under either one of the two equilibrium regimes (choosing pollution taxes and regulating minimum quality levels). The basic details of the time path of the planner's choices of qualities and level of pollution are displayed in Figure 3. Note that the equilibrium path of pollution displays the U shape pattern that Grossman and Krueger (1995) find for some pollutants.

The planner's allocation is such that pollution converges to a long-run level $s_{p}^{*}$. This level is strictly greater than the long-run level in either one of the voting solutions (they are the same). Thus, it follows that the planner's allocation entails strictly more pollution per unit of output than the equilibrium allocation when people vote over minimum quality. It is more difficult to determine how the planner's solution compares with the equilibrium solution when taxes are the instrument. All that can be said is that for very high levels of capital (and, hence, income) the planner's choice of pollution is higher than the equilibrium. Thus, at least for high levels of income, the models predict excessive conservation associated with the equilibrium solutions. The reason the planner chooses more pollution in the limit is easy to ascertain: the planner cares about future generations more than voters do. In this setting in which there are no intergenerational spillovers of pollution, voters fail to take into account the impact of the more expensive capital on the welfare of future generations. Note that as the discount factor in the planner's problem is driven to zero, all three solutions coincide in the long run. 


\section{Comments, Extensions, and Conclusions}

(1) Endogenous Policies and Convergence. Our focus to this point has been on the relationship between pollution, income, and growth. In addition to this, the model has implications about the relationship between income levels at time $t$ and the growth rate between $t$ and $t+k$. This is exactly the kind of relationship that has been the focus of the convergence literature. One position (see, for example, Barro and Sala-i-Martin (1995)) emphasizes that exogenous growth models imply conditional convergence, that is, that future growth is negatively correlated with current income level, once other factors are controlled for. Hence, finding a negative coefficient on income would be support for the exogenous growth model. Overall, the empirical evidence on this is inconclusive. The studies summarized in Barro and Sala-i-Martin (1995) seem to give support to the conditional convergence hypothesis, while Durlauf and Johnson (1995) and Quah (1996), using a different technique, find convergence clubs, that is, groups of countries that have similar behavior, but no overall convergence. There is no uniform theoretical result on the sign of this coefficient in the endogenous growth literature. Simple $A k$ models with exogenous (and stationary) policies have the implication that there should be no relationship between income levels and growth rates, while in other models of endogenous growth, this relationship can be either increasing (see Romer (1986)) or decreasing (see Jones and Manuelli (1990) and Boldrin and Rustichini (1994)).

What the model we analyze here shows is that when policies are endogenously chosen, virtually any result is possible, even in a model in which, if policies were exogenous and constant, the growth rate would be independent of the level of income. Indeed, we show that the model in which policies are endogenous can generate empirical convergence clubs, even though, in the long run, all countries will have the same policies and, hence, the same growth rate. To see 
this, we concentrate on the effluent charge equilibria of Sections 2 and 3. From the calculations in Appendix A, it follows that the mapping between the tax variable, $y$, and the growth rate of capital, $\gamma(y)$, changes depending on whether the tax rate lies above or below the threshold $\tau_{L}$ (that is, $y$ is less than or greater than one). Although this relationship is a complicated one (see Appendix A), several qualitative properties can be determined. First, under some parameter restrictions-basically, the magnitude of the productivity parameter A-the model displays positive growth, in the sense that for all $y, \gamma(y)>1$. Second, $\gamma(0)>\lim _{y \rightarrow \infty} \gamma(y)>1$; that is, high taxes decrease growth-relative to zero taxes—but do not stifle it altogether. Third, the growth rate of capital is increasing for values of $\tau$ that fall short of $\tau_{L}(y<1)$, while it is decreasing for values of $\tau>\tau_{L}(y>1)$ : for values of $y<1$, a tax increase induces a reallocation effect, because more capital is devoted to investment and less to the production of consumption goods. This increases the growth rate. In the region $y \geq 1$, higher taxes result in higher quality capital goods being demanded by the consumption sector (in smaller quantities though). This implies that less capital is allocated to the investment sector, decreasing the growth rate. An example of the function $\gamma(y)$ is shown in Figure 4.

The relationship between the current level of income and its future growth is not simple, but it is relatively simple to describe the relationship between the level of income at time $t$ and the growth rate of total capital between $t$ and $t+1$ (half a generation in our model). Consider, as before, an economy that starts out at a low level of income ( $k$ is low). This economy chooses no pollution taxes $(y=0)$, and the growth rate of capital is given by $\gamma(0)$ in Figure 4 . For a period of time-more precisely, between $t=0$ and $t=t_{0}^{*}$-income grows at a constant rate. Thus, in this region, the implication of the model is that growth rates are independent of income levels. How- 
ever, after $t_{0}^{*}$, the equilibrium is such that low but positive taxes are chosen (this is the region in which $0<y_{t}<1$ ). Moderate taxation of capital used in consumption induces more investment and a growth boom. Thus, in this region, the model implies that growth rates increase with the level of income and the average incomes of low and middle income countries grow farther apart. Finally, the economy enters the region in which taxes are high $\left(y_{t}>1\right)$, a region that is never left. In this region, the higher the initial level of income, the lower the subsequent growth rate. Thus, in this region, the model predicts conditional convergence of growth rates of capital, that is, a convergence club for high income countries.

Even though this is a very simple model and emphasizes only pollution taxes, we suspect that the mechanisms that we describe are relevant in models that emphasize endogenous determination of utility producing publicly provided goods (nonhomotheticity of utility may be important as well). Our results imply that care must be taken in the interpretation of convergence regressions. In particular, the convergence coefficient depends on initial income and could take any value-including divergence-depending on the mix of countries in the different regions. In addition, models of this type also suggest that it is possible to find convergence clubs in the data, without the usual implication associated with those findings-for example, rich countries (those with $y_{t}$ strictly greater than one) would form a convergence club.

Thus, the model is consistent with different policies driving differences in per capita income and growth across countries. Indeed, the model provides a theory for the differences-differences in levels of income across countries give rise to differences in selected policies, implying differences in growth rates.

(2) Heterogeneity. The assumption of identical individuals is convenient, but not essential. First, if individuals differed in terms of initial wealth—say, due to differences in their labor endow- 
ment or government transfers-our results in Sections 2 and 4 go through as they are. The key observation is that the relevant voting function, even in this case, depends on just the amount of pollution and the unit price of capital. If individuals have different disutility from pollution (different $u$ functions), then additional assumptions to guarantee that the median voter theorem holds are necessary. Given those assumptions, the analysis proceeds as in Sections 2 and 4. Finally, if the young cared about pollution but either cannot vote or are never the median voter, our positive analysis goes through without any changes. However, the normative analysis of Section 5 needs to be revised. In particular, the conclusion that the asymptotic level of pollution in the planner's solution exceeds that of the market need no longer hold.

(3) The Nature of Pollution. Throughout the paper, we assumed that pollution is a flow: the amount of smoke generated today affects only today's utility. If, instead, pollution is treated as a capital stock in which the amount produced at time $t$ increases that stock, the analysis in Sections 2 and 3, and hence the qualitative features of the model, remains basically unchanged. In this case, however, the welfare comparisons are more difficult.

(4) The Uses of Tax Revenue. In the analysis of Sections 2 and 3, we assumed that the proceeds from the environmental tax are thrown away (or, alternatively, used to finance a public good whose utility is separable with respect to the other variables). There are at least three simple alternatives: use the proceeds to clean the environment, make a transfer to the young, or make a transfer to the old. In the first case-and depending on how the cleaning up technology is specified-the qualitative results remain the same. If the tax revenue is used to finance a transfer to the young, it is possible to obtain the puzzling result that higher taxes increase the growth rate. This is a standard result in overlapping generations models (see Boldrin (1992) and Jones and Manuelli (1992)). Finally, if the proceeds from taxing low quality capital are used to finance a 
transfer to the old, the problem becomes substantially more complicated: in this case, the saving function will depend on the interest rate; hence, the voting decision must be modeled as a complicated game with an uncountable number of agents. Even though this is an interesting (and realistic) situation, it seems to add a level of complication that is hard to justify.

(5) Alternative Technologies. In this paper, we studied the case in which different varieties of capital used in the consumption sector generate pollution. An alternative would be to consider clean and dirty capital goods that can be used in both sectors. There are problems with these alternative specifications. If there are multiple capital goods in the production sector, it is possible that the voting problem is not well defined. The reason for this is simple: by increasing the price of capital (say, through higher taxes), the old increase their consumption while at the same time reducing pollution. In this setting, the optimal tax is infinite. Alternatively, one can consider multiple capital goods in the consumption sector. The problem in this case is that tax increases cause a reallocation to the capital sector, increasing the growth rate. Therefore, such a model would have the implication that higher pollution taxes are growth enhancing. Since this is at odds with the evidence, we decided against this approach.

(6) Global External Effects. The model can be easily extended to one in which pollution is global. In this case, and for a small country, the level of pollution is independent of local activities. It is straightforward to show that in this case, no local pollution controls are enacted. Thus, control of global pollutants requires worldwide collective decision-making mechanisms, and it is not clear that a voting model is appropriate for this. 


\section{Appendix A: Equilibrium for a Given $\left\{\tau_{t}\right\}$}

In this Appendix, we describe the equilibrium of the model for a given sequence of taxes $\left\{\tau_{t}\right\}$. Let $r_{I t}$ be the rental rate for renting capital to use in the production of new capital $\left(x_{t}\right)$, and let $p_{k t}$ be the price of new capital produced at time $t$. Profit maximization requires the following:

(A.1) $r_{k t}(z) \leq m(z) r_{I t}$, with equality if variety $z$ is produced,

and

(A.2) $r_{I t} / A \geq p_{k t}$, with equality if new capital is produced.

From Proposition 1, we know that producers of consumption goods will choose, at time $t$, only one quality of capital, which we denote by either $z_{t}$ or $z\left(\tau_{t}\right)$ as given in Proposition 1 . For firms in the consumption sector, the rental price of capital (after taxes) must equal the marginal product of capital. That is,

(A.3) $\alpha B k_{c t}\left(z_{t}\right)^{\alpha-1}=\left(1+\tau_{t} \phi\left(z_{t}\right)\right) r_{k t}\left(z_{t}\right)=\left(1+\tau_{t} \phi\left(z_{t}\right)\right) m\left(z_{t}\right) r_{I t}$.

Hence, using the equilibrium condition from the capital-producing sector,

(A.4) $p_{k t}=\frac{r_{I t}}{A}=\frac{1}{A} \frac{\alpha B k_{c t}\left(z_{t}\right)^{\alpha-1}}{\left(1+\tau_{t} \phi\left(z_{t}\right)\right) m\left(z_{t}\right)}$.

Imposing the equality of savings with the value of capital taken into time $t+1, b_{t}=$ $p_{k t} k_{t+1}$, and using the equilibrium condition that the wage rate is given by the marginal product of labor, we have that

$$
p_{k t} k_{t+1}=\frac{\beta}{1+\beta} w_{t}, \text { where } w_{t}=(1-\alpha) B k_{c t}\left(z_{t}\right)^{\alpha} .
$$

After some algebra, this implies that

(A.5) $k_{c t}\left(z_{t}\right)=\frac{\alpha}{1-\alpha} \frac{1+\beta}{\beta A} \frac{k_{t+1}}{\left(1+\tau_{t} \phi\left(z_{t}\right)\right) m\left(z_{t}\right)}$. 
Since $m\left(z_{t}\right) k_{c t}\left(z_{t}\right)+x_{t}=k_{t}$, we can rewrite, after substitution, the law of motion for $k$ as

$$
k_{t+1}=(1-\delta+A) k_{t}+k_{c t}\left(z_{t}\right)\left[(1-\delta)\left(1-m\left(z_{t}\right)\right)-A m\left(z_{t}\right)\right] .
$$

Using (A.5) in the above equation gives

$$
k_{t+1}=(1-\delta+\mathrm{A}) k_{t}+k_{t+1} \frac{\alpha(1+\beta)\left[(1-\delta)\left(1-m\left(z_{t}\right)\right)-A m\left(z_{t}\right)\right]}{(1-\alpha) \beta A\left(1+\tau_{t} \phi\left(z_{t}\right)\right) m\left(z_{t}\right)} .
$$

It follows that the growth rate of capital between time $t$ and time $t+1$ depends on the tax rate chosen at time $t$. The precise expression is

(A.7) $\gamma\left(\tau_{t}\right)=\gamma_{k t}=\frac{k_{t+1}}{k_{t}}=\frac{(1-\delta+A)}{1+\frac{\alpha(1+\beta)\left[(1-\delta)\left(m\left(z_{t}\right)-1\right)+A m\left(z_{t}\right)\right]}{(1-\alpha) \beta A\left(1+\tau_{t} \phi\left(z_{t}\right)\right) m\left(z_{t}\right)}}$,

where the dependence of $z_{t}$ on the tax rate is described in Proposition 1. Equations (A.5) and (A.7) imply that the equilibrium relationship between $k_{c t}(z)$ and $k_{t}$ is given by

$$
k_{c t}\left(z_{t}\right)=\frac{\alpha}{(1-\alpha)} \frac{(1+\beta)}{\beta A} \frac{(1-\delta+A) k_{t}}{\left(1+\tau_{t} \phi\left(z_{t}\right)\right) m\left(z_{t}\right)+\frac{a}{(1-\alpha)} \frac{(1+\beta)}{\beta A}\left[(1-\delta)\left(m\left(z_{t}\right)-1\right)+A m\left(z_{t}\right)\right] .}
$$

Given the ratio $k_{c} / k$ and $\phi$ and substituting in the expression for $y$, it follows that the unit price of capital, $p_{k \tau}(y)$, and pollution per unit of total capital, $\mu_{\tau}(y)$, are given by

$$
p_{k \tau}(y)= \begin{cases}p_{k 1}(y)=K \frac{\left[\left(1+\frac{\theta}{v-\theta} y^{v / \theta}\right)+\frac{\alpha}{1-\alpha} \frac{1+\beta}{\beta}\right]^{1-\alpha}}{\left(1+\frac{\theta}{v-\theta} y^{v / \theta}\right)} & \text { for } y \leq 1 \\ p_{k 2}(y)=K \frac{\left[\left(1+\frac{\theta}{v-\theta}\right) y+\frac{\alpha}{1-\alpha} \frac{1+\beta}{\beta A}((1-\delta+A) y-(1-\delta))\right]^{1-\alpha}}{\left(1+\frac{\theta}{v-\theta}\right) y} & \text { for } y \geq 1\end{cases}
$$


(A.10) $\mu_{\tau}(y)= \begin{cases}\mu_{1}(y)=\frac{\alpha(1+\beta)(1-\delta+A) D}{(1-\alpha) \beta A\left[\left(1+\frac{\theta}{v-\theta} y^{v / \theta}\right)+\frac{\alpha}{1-\alpha} \frac{1+\beta}{\beta}\right]} & \text { for } y \leq 1 \\ \mu_{2}(y)=\frac{\alpha(1+\beta)(1-\delta+A) D y^{-v / \theta}}{(1-\alpha) \beta A\left[\left(1+\frac{\theta}{v-\theta}\right) y+\frac{\alpha}{1-\alpha} \frac{1+\beta}{\beta A}((1-\delta+A) y-(1-\delta))\right]} & \text { for } y \geq 1\end{cases}$ where $K$ is a constant. 


\section{Appendix B: Proofs}

Proof of Proposition 1: The first-order condition for cost minimization is

$$
\begin{aligned}
& \theta(1+z)^{\theta-1}\left(1+\tau D(1+z)^{-v}\right)+(1+z)^{\theta}(-v) \tau D(1+z)^{-(v+1)} \\
& =(1+z)^{\theta-1}\left[\theta\left(1+\tau D(1+z)^{-v}\right)-v(1+z)^{-v} \tau D\right]
\end{aligned}
$$

When $\tau=0$, this is $(1+z)^{\theta-1} \theta>0$ for all $z \geq 0$. This implies that $z(\tau)=0$ for sufficiently

small $\tau$. Note that, as defined, $\tau_{L}$ satisfies $\left[\theta\left(1+\tau_{L} D\right)-v \tau_{L} D\right]=0$.

For $\tau \geq \tau_{L}, z$ is interior. After substitution, we get

$$
z=\left(\frac{(v-\theta) \tau D}{\theta}\right)^{1 / v}-1
$$

\section{Proof of Proposition 2: Let}

$$
V(y, k)= \begin{cases}V_{1}(y, k) & \text { for } y \leq 1 \\ V_{2}(y, k) & \text { for } y \geq 1\end{cases}
$$

where $V_{i}(y, k) \equiv \ln \left(p_{k i}(y)\right)-u\left(\mu_{i}(y) k\right)$. The maximized value of $V$, denoted by $V^{*}(k) \equiv V(y(k), k)$, where $y(k)$ is the optimal choice of $y$ given $k$, is given by $V^{*}(k)=\max _{\{i=1,2\}} V_{i}^{*}(k) . V_{i}^{*}(k)$ is just the maximum of $V_{i}$ over the relevant domain for $y$; that is, $0 \leq y \leq 1$ for $i=1$ and $y \geq 1$ for $I=2$. The maximizers are denoted by $y_{1}(k)$ and $y_{2}(k)$, respectively. It follows that $V_{i}^{*}(k)=V_{i}\left(y_{i}(k), k\right)$ for $i=1,2$.

It is convenient to restate Proposition 2 using the notation introduced above. To prove the proposition, it suffices to prove that the maximum of $V(y, k)$ is well defined for all $k \geq 0$. The maximizer, $y(k)$, has the following properties:

(a) $\exists k_{B}>0$, such that $\forall k \leq k_{B}, y(k)=y_{1}(k)=0$. 
(b) $\exists k_{C}$, such that for all $k \geq k_{C}, y(k)=y_{2}(k)$, which is strictly increasing, is continuous, and $\lim _{k \rightarrow \infty} y(k)=\infty$.

(c) For all $k, y_{2}(k)>y_{1}(k)$.

(d) There exist $k_{D}$ and $k_{E}$, such that for all $k \in\left(k_{D}, k_{E}\right), y_{1}(k)$ is interior.

(e) If in addition to Assumption A, $y_{1}(k)$ is differentiable, there exists a unique $k_{F}$, such that $y(k)=y_{1}(k)$ for $k \leq k_{F}$ and $y(k)=y_{2}(k)$ for $k \geq k_{F}$.

Note that (a)-(c) imply properties (i)-(iii), (d) implies (iv), and (e) implies (v). We are now ready to prove the result. First, we first characterize $y_{1}(k)$ and $y_{2}(k)$. (See Figure 5.)

Consider $\max _{0 \leq y \leq 1} V_{1}(y, k)$. Given that the function is continuous, existence and upperhemicontinuity of $y_{1}(k)$ - the maximizer of $V_{1}$ in the region [0,1] as a function of $k$-follows from the maximum theorem. The function $V_{1}$ is differentiable, and it can be checked that $\partial_{2} V_{1} / \partial y \partial k \geq 0$ (with the inequality being strict if $k>0$ ). Thus, the function is supermodular. The results of Topkis (1978) and Milgrom and Shannon (1994) show that the maxim and $y_{1}$ is monotone increasing.

A straightforward calculation shows that

$$
\partial V_{1} / \partial_{y}=\left(\mu_{1}^{\prime} / \mu_{1}\right)\left[\zeta-u^{\prime}\left(\mu_{1} k\right) \mu_{1} k\right]
$$

Next consider

$$
H(k)=\max _{0 \leq y \leq 1}\left\{\zeta(y)-\mu^{\prime}\left(\mu_{1}(y) k\right) \mu_{1}(y) k\right\} .
$$

It follows that $\lim _{k \rightarrow 0} H(k)>0$ and $\lim _{k \rightarrow \infty} H(k)<0$. Thus, there exists some $k_{B 1}$, such that $k \leq k_{B 1}$ implies that $H(k) \geq 0$. Since $\partial V_{1} / \partial y \leq\left(\mu_{1}^{\prime} / \mu_{1} H(k)\right.$, this implies that $y_{1}(k)=0$ for $k \leq k_{B 1}$. We will later show that $y_{1}$ and $y$ coincide on an interval $\left[0, k_{B}\right]$ with $k_{B} \leq k_{B 1}$. 
Note that, as defined in the text, $k_{A}$ is the smallest $k$ such that $y_{1}(k)$ is one. Given the monotonicity result, it is also equal to one for $k \geq k_{A}$. That $k_{B 1}<k_{A}$ is simply guaranteed by Assumption A. In Figure 1, we show a candidate $y_{1}(k)$ function.

We now characterize the solution, $y_{2}(k)$, to the maximization of $V_{2}$. We need to consider two cases. If $y_{M}>1$, the function $V_{2}$ is clearly increasing in the region $\left[1, y_{M}\right]$. Thus, in this case, $y_{2} \geq y_{M}$. From an economic point of view, $y_{M}$ is a monopoly price of capital, and the old would never choose taxes that result in a price lower than this monopoly price. The second case is when $y_{M}=1$. This corresponds to a $p_{k 2}$ function that is decreasing. In this case, define $k_{C 1}$ as the largest value of $k$ such that $y_{2}(k)=1$. Then $k_{C 1}$ satisfies

$$
\beta\left(p_{k 2}^{\prime}(1) p_{k 2}(1)\right)\left(\mu_{2}(1) / \mu_{2}^{\prime}(1)\right)=u^{\prime}\left(\mu_{2}(1) k_{C 1}\right) \mu_{2}(1) k_{C 1} .
$$

It is easy to show that $V_{2}$ is supermodular as well and, hence, that $y_{2}$ is increasing. Moreover, inspection of the function $\beta\left(p_{k 2}^{\prime}(y) / p_{k 2}(y)\right)\left(\mu_{2}(y) / \mu_{2}^{\prime} \mu(y)\right)$ shows that it is monotone increasing for $y \geq y_{M}\left(y \geq 1\right.$ when $p_{k 2}$ is everywhere decreasing), while $u^{\prime}\left(\mu_{2}(y) k\right) \mu_{2}(y) k$ is decreasing. Since equality of these two functions is a necessary condition for an interior maximum $(y>1)$, it follows that the maximizer is unique and, hence, continuous. Simple inspection implies that $y_{2}(k) \rightarrow \infty$ as $k \rightarrow \infty$.

To prove property (iii), we show that $k_{C 1}<k_{B 1}$. Direct calculation shows that $p_{k 2}^{\prime}(1)>$ $p_{k 1}^{\prime}(1)$. From the definition of $k_{C 1}$ and $k_{B 1}$ and given that the functions $p_{k i}$ and $\mu_{i}$ are continuous at 1 , it follows that

$$
\mu_{2}^{\prime}(1) u^{\prime}\left(\mu_{2}(1) k_{C 1}\right) \mu_{2}(1) k_{C t}>\mu_{1}^{\prime}(1) u^{\prime}\left(\mu_{1}(1) k_{B 1}\right) \mu_{1}(1) k_{B 1} .
$$

Direct calculation shows that $\mu_{2}^{\prime}(1)<\mu_{1}^{\prime}(1)<0$. Thus, after some substitution, 
$u^{\prime}\left(\mu_{2}(1) k_{C 1}\right) \mu_{2}(1) k_{C 1}<u^{\prime}\left(\mu_{1}(1) k_{B 1}\right) \mu_{1}(1) k_{B 1}$.

The monotonicity of $u^{\prime}(x) x$ implies that $k_{C 1}<k_{B 1}$.

To complete the argument, we need to show that for low values of $k, V_{1}^{*}>V_{2}^{*}$, while the opposite holds for large values of $k$ (this is properties (i) and (ii)). First we show that for small $k$, $V_{1}^{*}>V_{2}^{*}$. Let $k \leq \min \left\{k_{B 1}, k_{C 1}\right\}$. Then

$V_{1}^{*}(k)=V_{1}(0, k)$ and $V_{2}^{*}(k)=V_{2}(1, k)$.

Thus, using the fact that $p_{k 1}(1)=p_{k 2}(1)$, we get

$$
V_{1}^{*}-V_{2}^{*}=\beta \ln \left(p_{k 1}(0) / p_{k 1}(1)\right)-\left[u\left(\mu_{1}(0) k\right)-u\left(\mu_{2}(1) k\right)\right]
$$

Note that the first term is strictly positive, while the second converges to zero as $k$ goes to zero. This completes the argument that $y=y_{1}$ for small $k$. Define $k_{B}$ as the largest such $k$.

Next we show that $V_{2}^{*}>V_{1}^{*}$ for large $k$. Let $k>\max \left\{k_{A}, k_{C 1}\right\}$, such that $y_{2}(k)>y^{*}>1$ and $y_{1}(k)=1($ see Figure 1$)$. Hence, $V_{2}(y, k)>V_{2}\left(y^{*}, k\right)$. Thus,

$$
V_{2}^{*}-V_{1}^{*} \geq V_{2}\left(y^{*}, k\right)-V_{1}(1, k)=\beta \ln \left(p_{k 2}\left(y^{*}\right) / p_{k 2}(1)\right)-\left[u\left(\mu_{2}\left(y^{*}\right) k\right)-u\left(\mu_{1}(1) k\right)\right] .
$$

Since the first term is bounded, it suffices to show that the second term (in square brackets) goes to $-\infty$ as $k$ grows. Since $u$ is convex, it follows that

$$
u\left(\mu_{1}(1) k\right)-u\left(\mu_{2}\left(y^{*}\right) k\right) \geq u^{\prime}\left(\mu_{2}\left(y^{*}\right) k\right) \mu_{2}\left(y^{*}\right) k\left[\left(\mu_{2}\left(y^{*}\right)-\mu_{1}(1)\right) / \mu_{2}\left(y^{*}\right)\right]
$$

and the result now follows from our assumptions on $u$.

To prove property (iv), consider the first-order condition for an interior maximum of $V_{1}$. It is given by

$$
\partial V_{1} / \partial y=\left(\mu_{1}^{\prime}(y) / \mu_{1}(y)\right)\left[\zeta(y)-u^{\prime}\left(\mu_{1}(y) k\right) \mu_{1}(y) k\right]=0 .
$$


It is sufficient to show that for some values of $k$ and $y$, the term in square brackets is zero. From Assumption A, this term is negative for some $k<k_{A}$ and some $y<1$. It is positive when evaluated at $y=1$ for this $k$. It follows that for this $k$, this term is zero for some $y$ in $(0,1)$. By continuity of $u^{\prime}$, it follows that this holds for an open set of $k$ 's.

To prove property (v), note that it is sufficient to show that if at some $k, y(k)=y_{2}(k)$, then $y\left(k^{\prime}\right)=y_{2}\left(k^{\prime}\right)$ for all $k^{\prime}>k$. To see that this holds, it is sufficient to show that $V_{2}^{*^{\prime}}>V_{1}^{*^{\prime}}$ for all k. To see that this holds, recall that $V_{i}^{*}=V_{i}\left(y_{i}(k) ; k\right)$, and so $V_{i}^{*^{\prime}}=\partial V_{i}(y ; k) / \partial y d y_{i} / d k+$ $\partial V_{i}(y ; k) / \partial k$. By the definition of $y_{i}$, it follows that the first term is zero; hence, it is sufficient to show that $\partial V_{2}(y ; k) / \partial k>\partial V_{1}(y ; k) / \partial k$. Straightforward calculations show that this is equivalent to showing that $\mu_{1}\left(y_{1}(k)\right)>\mu_{2}\left(y_{2}(k)\right)$ for all $k$. That this holds follows from the fact that both $\mu_{1}$ and $\mu_{2}$ are monotonically decreasing and that they are equal at $y=1$.

Proof of Proposition 4: We first characterize how the optimal $z$ varies with $k$. With this done, the assumption on parameters that imply that $k$ is strictly increasing over time results in the behavior of time paths as stated in the proposition. Using (4.1) and (4.2) as well as the indirect utility function $V_{q}$, it follows that

$$
\begin{aligned}
\partial V_{q} / \partial z= & \beta m^{\prime}(z) / m(z)\left\{\left[(1-\alpha) m(z) a_{0} /\left(a_{0} m(z)-a_{1}\right)\right]-1\right\}+ \\
& u^{\prime}\left(\mu_{q}(z) k\right) \mu_{q}(z) k\left[a_{0} m^{\prime}(z)+v(1+z)^{-1}\right] /\left[a_{0} m(z)-1\right] .
\end{aligned}
$$

Given our assumptions about $u$, the second term converges to zero as $k$ goes to zero. Thus, to establish that for small $k$ the equilibrium $z$ will be zero, it suffices to show that

$$
\beta m^{\prime}(z) / m(z)\left\{\left[(1-\alpha) m(z) a_{0} /\left(a_{0} m(z)-a_{1}\right)\right]-1\right\}>0 .
$$


Simple algebraic manipulations show that this inequality holds if and only if $m(z)>$ $a_{1} / \alpha a_{0}$

Note that the assumption $z_{M}=0$ requires that $1>a_{1} / \alpha a_{0}$, which completes the argument, because $m(z) \geq 1$.

Next we characterize the equilibrium $z$ as a function of $k$ when the solution is interior. Algebraic manipulation of the condition $\partial V_{q} / \partial z=0$ shows that it is equivalent to $S(z)=G(z, k)$, where

$$
G(z, k)=u^{\prime}\left(\mu_{q}(z) k\right) \mu_{q}(z) k
$$

and

$$
S(z)=\left[\left(a_{0} m(z)-a_{1}\right)-(1-\alpha)\right] /\left[(v / \theta)\left(a_{0} m(z)-a_{1}\right)+a_{0} m(z)\right] .
$$

It follows that $G(z, k)$ is decreasing in $z$ and increasing in $k$, while $S(z)$ is increasing in $z$. Thus, the optimal $z$ is unique and increases as $k$ increases. Moreover, as proved above, for small $k, G(0, k)<S(0)$, and so the equilibrium $z$ is zero.

Proof of Proposition 5: The planner's problem is

$$
\max W=\sum_{t=0}^{\infty} \beta_{P}^{t}\left[\ln \left(c_{t}^{t}\right)+\beta \ln \left(c_{t}^{t-1}\right)-u\left(s_{t+1}\right)\right]
$$

subject to

$$
\begin{aligned}
& c_{t}^{t}+c_{t}^{t-1} \leq B k_{c t}^{\alpha}, \\
& k_{t+1} \leq(1-\delta+A) k_{t}+\left[(1-\delta)-(1-\delta+A) m\left(z_{t}\right)\right] k_{c t}, \\
& \phi\left(z_{t}\right) k_{c t} \leq s_{t} .
\end{aligned}
$$

This statement of the planner's problem assumes that only one quality, $z_{t}$, is chosen at time $t$. A more general statement of the problem should allow for measures over values of $z$ as the relevant 
choice variable. Later in the proof, we state the problem in this more general framework and show that the optimum is such that only one quality is chosen at any given time.

After differentiation, some algebra, and some substitution, we get

$(\mathrm{P} .5 .1) \quad u^{\prime}\left(s_{t}\right) s_{t}=\alpha\left(\beta+\beta_{P}\right)(\theta / v)(1-\delta+A) m\left(z_{t}\right) /\left[(1+\theta / v)(1-\delta+A) m\left(z_{t}\right)-(1-\delta)\right]$.

Equation (P.5.1) completely summarizes the behavior of pollution in any interior solution. Direct calculation shows that the right-hand side of (P.5.1) is decreasing in $z_{t}$. Thus, if $z_{t}$ is increasing in equilibrium (we will show this to be the case), $s_{t}$ is decreasing. Taking into account that $s_{t}=\phi\left(z_{t}\right) k_{c t}$, it follows from (P.5.1) that if $\lim _{t \rightarrow \infty} k_{c t}=\infty$ (we will show this to be the case as well), then $\lim _{z \rightarrow \infty} z_{t}=\infty$. That $k_{c t} \rightarrow \infty$ also follows from the first-order conditions of the planner's problem along with the assumption that $\beta_{P}(1-\delta+A)>1$.

The limit of the right-hand side of (P.5.1) as $z \rightarrow \infty$ is $\left(\beta+\beta_{P}\right) \alpha /(1+v / \theta)$. Thus, it follows that $s_{t}$ is decreasing (if $z_{t}>0$ ) and converges to $s_{p}^{*}$, where

$$
u^{\prime}\left(s_{p}^{*}\right) s_{p}^{*}=\left(\beta+\beta_{P}\right) \alpha /(1+v / \theta) .
$$

Finally, we show that for small $k$, the optimal solution is a corner solution with $z=0$. Using the relevant version of the first-order conditions, the appropriate version of (P.5.1) is

$$
\left(\mathrm{P} .5 .1^{\prime}\right) \quad u^{\prime}\left(\phi(0) k_{c t}\right) \phi(0) k_{c t}<\alpha\left(\beta+\beta_{P}\right)(\theta / v)(1-\delta+A) /[(1+\theta / v)(1-\delta+A)-(1-\delta)],
$$

which clearly must hold for small $k$ since $k_{c}$ is bounded above by $k$ and the left-hand side is converging to 0 as $k_{c} \rightarrow 0$.

To complete the proof, we show that $z_{t}$ is indeed increasing (and in passing we also show that only one $z$ is chosen at time $t$ ). To do this, it is convenient to write the planner's problem as a dynamic problem with the choice variable being a measure, $\mu$, over the space of possible qualities (which we denote by $Z$ ), with the interpretation that $\mu(\{z\})$ is the amount of capital of type $z$ 
that the planner allocates to the consumption sector. With this relabeling, the appropriate version of Bellman's equation for the planner's problem is

(P.5.2) $V(k)=\max _{\mu, x, k^{\prime}}\left\{f(\mu)+\beta V\left(k^{\prime}\right)\right\}$

subject to

$$
\begin{aligned}
& k \geq \int m(z) \mu(d z)+x, \\
& k^{\prime} \leq(1-\delta)\left[\int \mu(d z)+x\right]+A x .
\end{aligned}
$$

Here, $f(\mu)$ is the indirect utility function when $c_{y}, c_{0}$, and $s$ have been maximized out.

Standard arguments imply that $f$ is a strictly concave function of $\mu, V(k)$ is strictly concave, and $V$ is differentiable when the solution is interior.

Even though we stated the planner's problem in a general way by allowing measures to be the choice variable, since both $m(z)$ and $\phi(z)$ are convex $(\phi(z)$ is strictly convex), a direct application of Jensen's inequality establishes that a point mass measure on some $z_{t}$ dominates any measure that puts positive mass on more than one point. Thus, the optimal measure is one that puts mass $k_{c t}$ on the set $\left\{z_{t}\right\}$, where $k_{c t}$ and $z_{t}$ are the variables characterized in the planner's problem at the beginning of the proof.

Finally, to establish that the sequence $z_{t}$ is increasing when it is interior (we already showed that there is a region in which it is zero), rewrite the planner's problem as

$$
\max \left\{C_{0}+\alpha(1+\beta) \ln \left(k_{c}\right)-u\left(\phi(z) k_{c}\right)+\beta V\left[(1-\delta) k_{c}-(1-\delta+A)\left(k-m(z) k_{c}\right]\right\}\right.
$$

where $C_{0}$ is a constant. This formulation already incorporates the result that the choice of $z$ is unique. Let the function inside set brackets be denoted by $M\left(k_{c}, z ; k\right)$. It follows from the concavity of $V$ that the function is supermodular (see Topkis (1979) and Milgrom and Shannon (1994)) 
and, hence, that higher values of $k$ result in higher values of $z$. However, since the growth rate is positive, the sequence $k_{t}$ is increasing. Thus, the sequence $z_{t}$ increases as well. 


\section{References}

Alesina, A. and D. Rodrik. (1994). "Distributive Politics and Economic Growth," Quarterly Journal of Economics 109 (May): 465-90.

Barro, R.J. and X. Sala-i-Martin. (1995). Economic Growth. New York: McGraw-Hill.

Baumol, W.J. and W.E. Oates. (1988). The Theory of Environmental Policy. 2nd edition. Cambridge: Cambridge University Press.

Boldrin, M. (1992). “Dynamic Externalities, Multiple Equilibria, and Growth,” Journal of Economic Theory 58 (December): 198-218.

Boldrin, M. and A. Rustichini. (1994). "Growth and Indeterminacy in Dynamic Models with Externalities," Econometrica 62 (March): 323-43.

Cho, D. (1996). “An Alternative Interpretation of Conditional Convergence Results,” Journal of Money, Credit, and Banking 28 (November, Part 1): 669-81.

Durlauf, S.N. and P.A. Johnson. (1995). "Multiple Regimes and Cross-Country Growth Behavior," Journal of Applied Econometrics 10 (October-December): 365-84.

Easterly, W. (1994). "Economic Stagnation, Fixed Factors, and Policy Thresholds," Journal of Monetary Economics 33 (June): 525-57.

Fisher, E.O. and C. van Marrewijk. (1994). "Pollution and Economic Growth in a Model of Overlapping Generations," Working Paper, Ohio State University.

Glomm, G. and B. Ravikumar. (1992). "Public Versus Private Investment in Human Capital: Endogenous Growth and Income Inequality," Journal of Political Economy 100 (August): 818-34.

Glomm, G. and B. Ravikumar. (1995). "Endogenous Public Policy and Multiple Equilibria," European Journal of Political Economy 11 (December): 653-62. 
Grossman, G.M. and A.B. Krueger. (1995). "Economic Growth and the Environment," Quarterly Journal of Economics 110 (May): 353-77.

Jones, L.E. and R.E. Manuelli. (1990). “A Convex Model of Equilibrium Growth: Theory and Policy Implications," Journal of Political Economy 98 (October, Part 1): 1008-38.

Jones, L.E. and R.E. Manuelli. (1992). "Finite Lifetimes and Growth," Journal of Economic Theory 58 (December): 171-97.

Krusell, P., V. Quadrini, and J.-V. Rios-Rull. (1997). "Politico-Economic Equilibrium and Economic Growth,” Journal of Economic Dynamics and Control 21 (January): 243-72.

Levinson, A. (1996). “Environmental Regulations and Manufacturers' Location Choices: Evidence From the Census of Manufactures," Journal of Public Economics 62 (October): 529.

Low, P. and A. Yeats. (1992). “Do 'Dirty' Industries Migrate?” in Low, P. (ed.) International Trade and the Environment. World Bank Discussion Papers, No. 159, pp. 89-103. Washington, D.C.: World Bank.

Lucas, R.E.B., D. Wheeler, and H. Hettige. (1992). "Economic Development, Environmental Regulation and the International Migration of Toxic Industrial Pollution: 1960-88," in Low, P. (ed.) International Trade and the Environment. World Bank Discussion Papers, No. 159, pp. 67-86. Washington, D.C.: World Bank.

Milgrom, P. and C. Shannon. (1994). “Monotone Comparative Statics,” Econometrica 62 (January): $157-80$.

Mohtadi, H. (1994). "Environment, Development and Growth: Explaining the Evidence and Designing Optimal Policies,” Working Paper, University of Wisconsin-Milwaukee. 
Persson, T. and G. Tabellini. (1994). “Is Inequality Harmful for Growth?” American Economic Review 84 (June): 600-21.

Quah, D.T. (1996). "Convergence Empirics Across Economies with (Some) Capital Mobility," Journal of Economic Growth 1 (March): 95-124.

Romer, P.M. (1986). “Increasing Returns and Long-Run Growth,” Journal of Political Economy 94 (October): 1002-37.

Stokey, N.L. (1998). “Are There Limits to Growth?” International Economic Review 39 (February): $1-31$.

Topkis, D.M. (1978). “Minimizing a Submodular Function on a Lattice,” Operations Research 26: $305-21$.

U.S. Environmental Protection Agency. (1995). “A Look at EPA Accomplishments: 25 Years of Protecting Public Health and the Environment," Washington, D.C.: U.S. Environmental Protection Agency.

Wheeler, D. (1992). “The Economics of Industrial Pollution Control: An International Perspective," Working Paper, World Bank.

World Bank. (1992). World Development Report 1992: Development and the Environment. New York: Oxford University Press. 


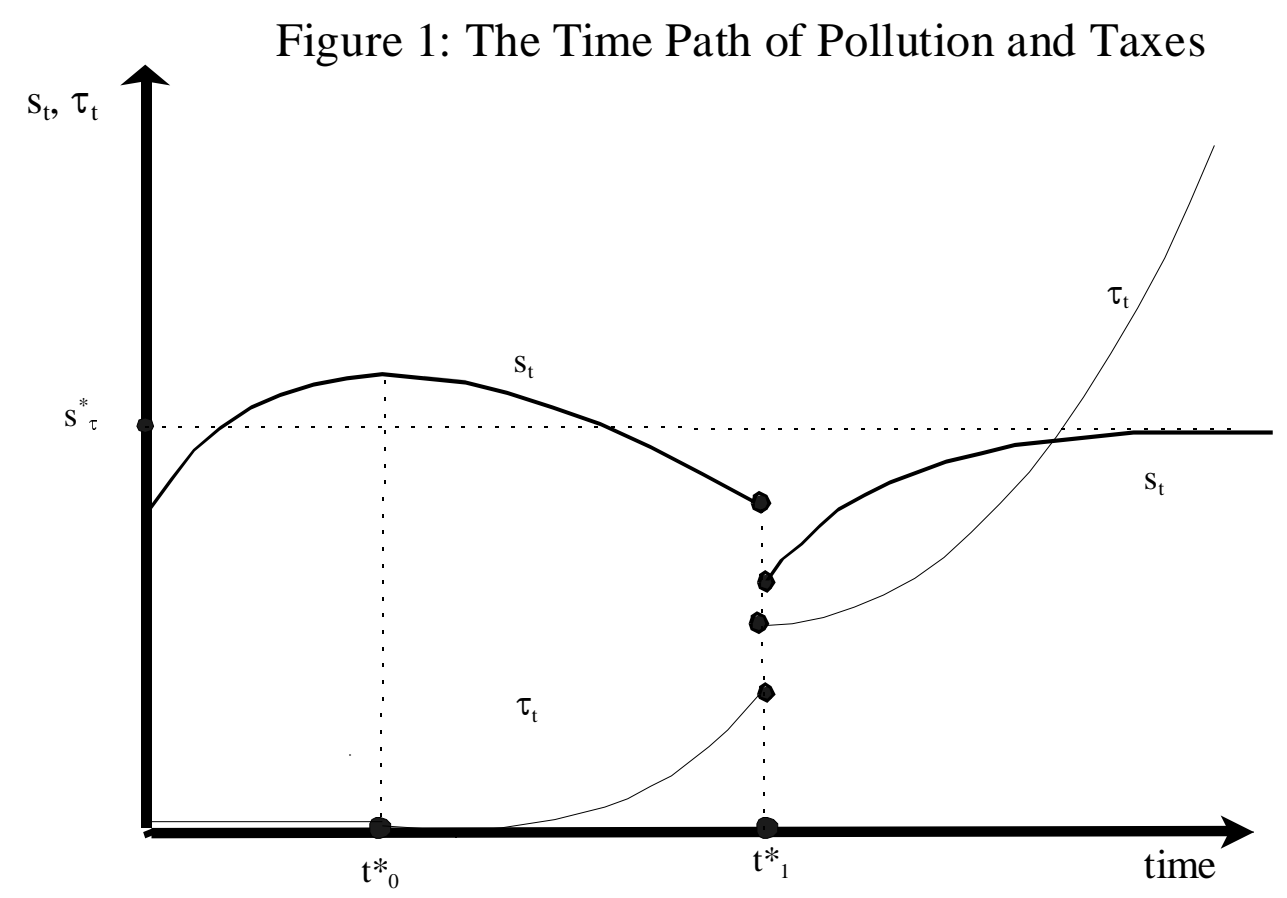


Figure 2: Voting over Qualities: Pollution and z

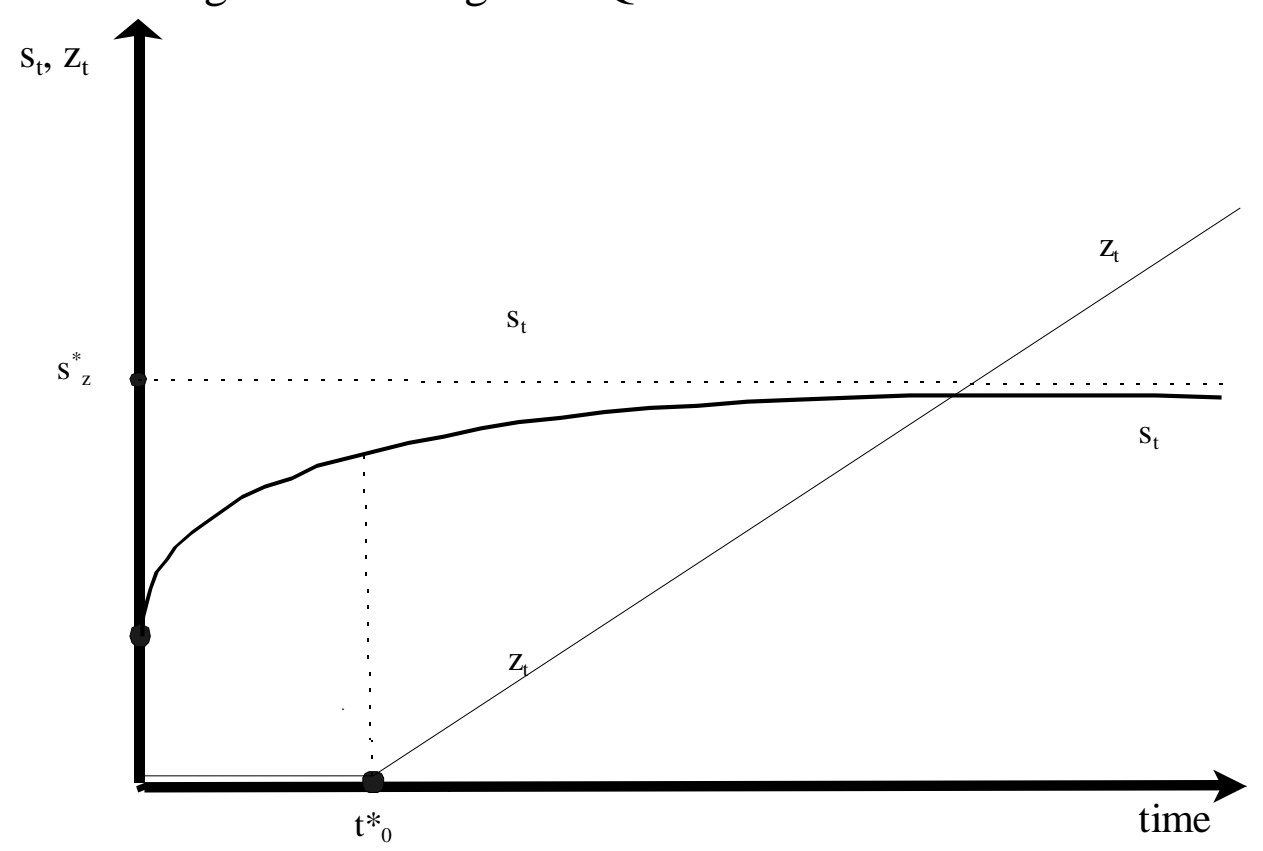


Figure 3: Planner's Problem: Pollution and $\mathrm{z}$

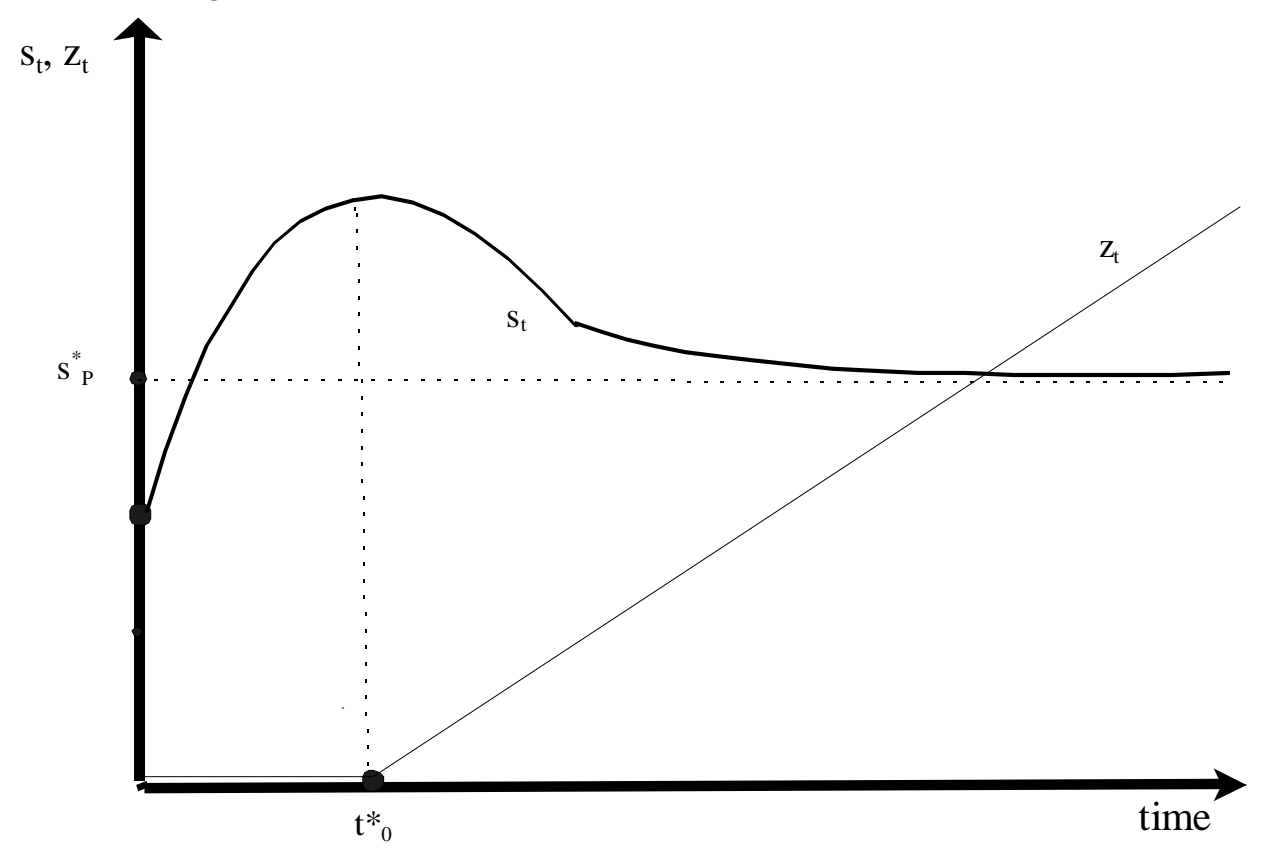




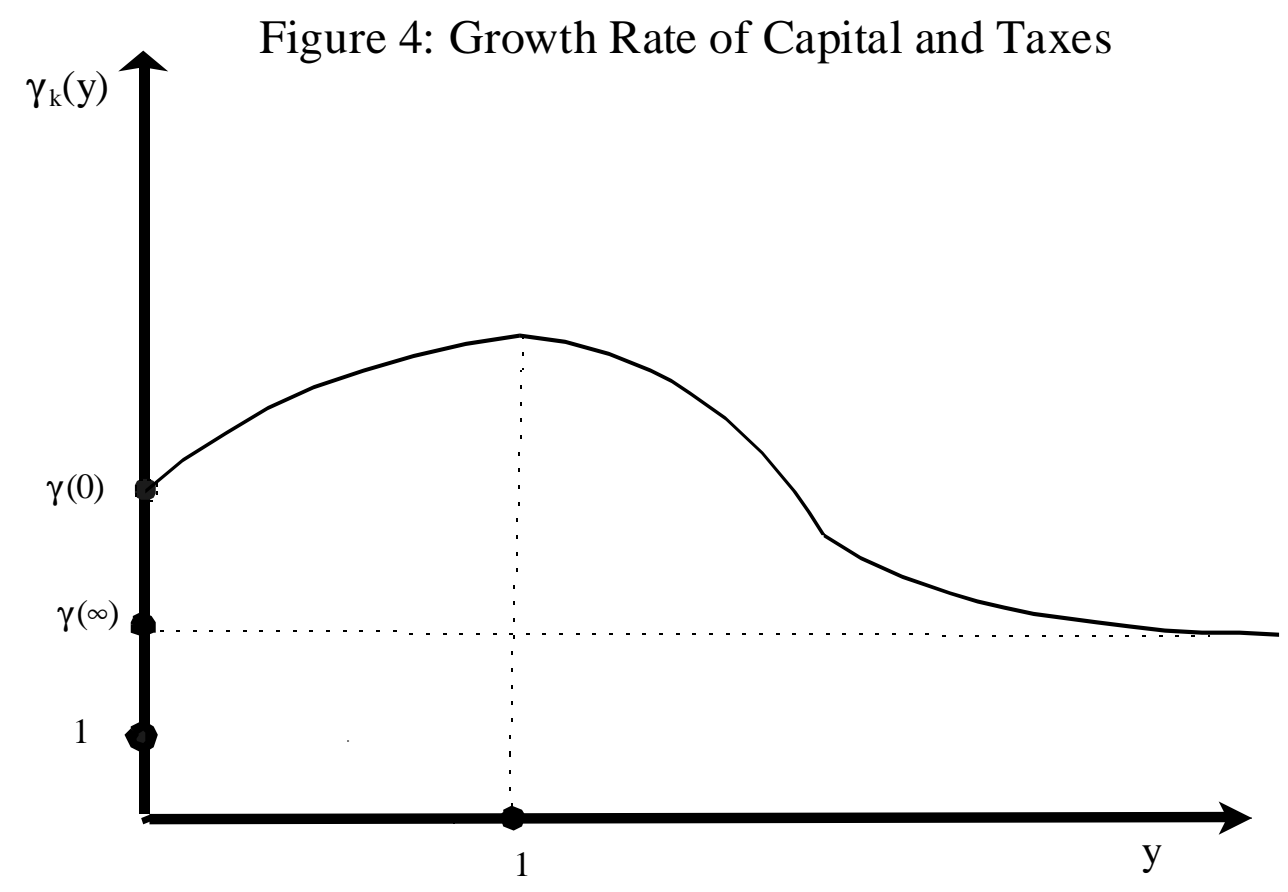




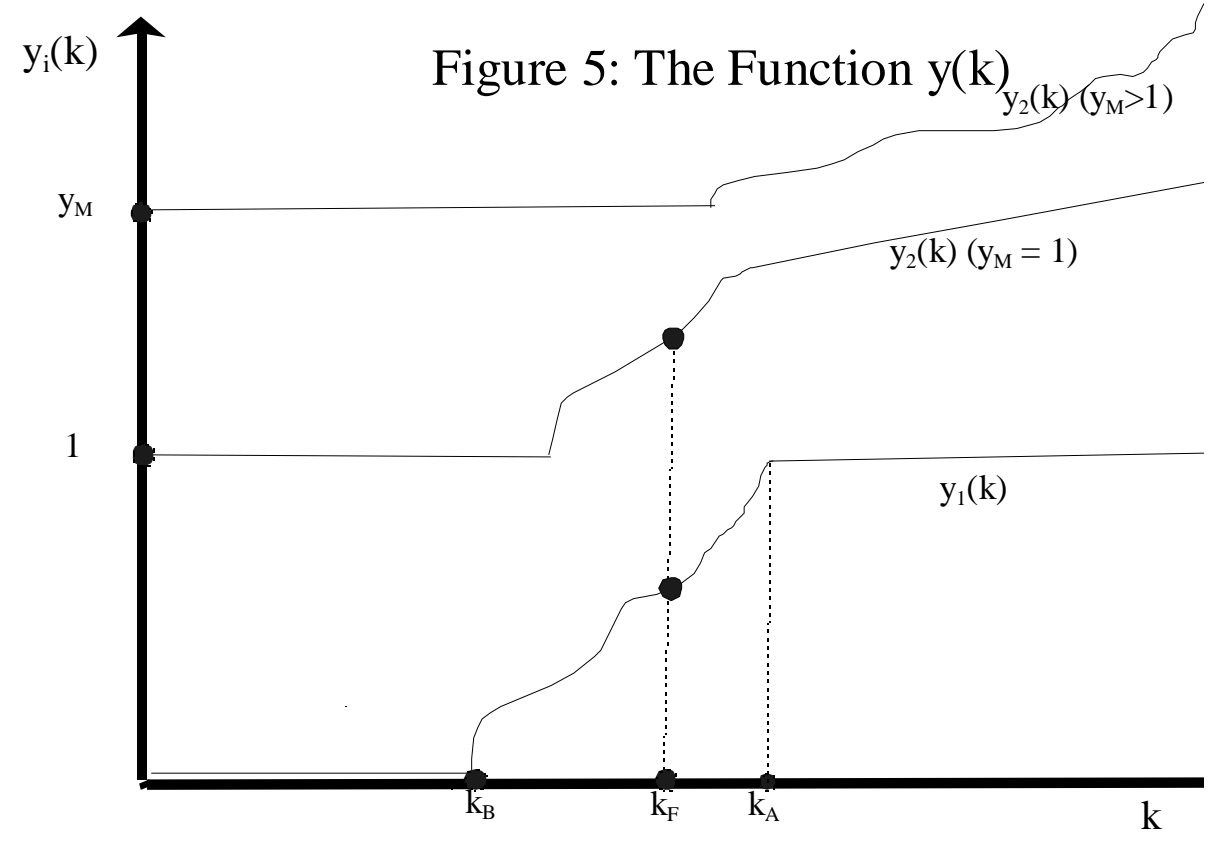

